\title{
Determination of Volatile Organic Compounds in Andean Tomato Landraces by Headspace Solid Phase Microextraction-Gas Chromatography-Mass Spectrometry
}

\author{
Pablo R. Cortina, ${ }^{a}$ Ramón Asis, ${ }^{b}$ Iris E. Peralta,${ }^{c, d}$ Pablo D. Asprelli ${ }^{d, e}$ and Ana N. Santiago ${ }^{*, a}$ \\ ${ }^{a} I N F I Q C$, Departamento de Química Orgánica and ${ }^{b} C I B I C I$, Departamento de Bioquímica Clínica, \\ Facultad de Ciencias Químicas, Universidad Nacional de Córdoba, Ciudad Universitaria, \\ 5000 Córdoba, Argentina
}

\author{
'IADIZA CCT CONICET Mendoza, Parque General San Martín, 5500 Mendoza, Argentina \\ ${ }^{d}$ Facultad de Ciencias Agrarias, Universidad Nacional de Cuyo y CCT CONICET Mendoza, \\ Chacras de Coria, Luján de Cuyo, 5505 Mendoza, Argentina
}

${ }^{e}$ EEA La Consulta, INTA, La Consulta, San Carlos, 5567 Mendoza, Argentina

\begin{abstract}
Traditional tomatoes (Solanum lycopersicum L.) have been mainly selected for their fruit quality and maintained by local farmers in Andean areas of Cuyo and Northwestern Argentina. Volatile organic compounds (VOCs) in mature fruits of Andean tomato landraces were evaluated for the first time using headspace solid phase microextraction (HS-SPME) and gas chromatographymass spectrometry (GC-MS) and combined with classical multivariate analysis. The data sets composed of 101 volatile metabolites were identified in 4 accessions of Andean landraces, one commercial variety and one wild tomato accession (Solanum pimpinellifolium L.). The metabolic profile showed typical VOCs of tomato and 21 new compounds never informed in S. lycopersicum. Andean traditional tomatoes have been shown to be metabolically different from wild species. In addition, some varieties of Andean tomatoes have a different profile of VOCs and are richer than the commercial variety. A different and original metabolic volatile composition found in fruits of Andean tomato landraces of Argentina, in comparison with commercial cultivars, might probably reveals selection based on quality attributes made by local farmers.
\end{abstract}

Keywords: tomato, fruit, SPME, volatile metabolites, multivariate analysis

\section{Introduction}

The study of volatile organic compounds (VOCs) in fruits and vegetables poses a continuous analytical challenge. Some problems are due to the low levels of VOCs present in complex matrices, together with their large chemical diversity. In recent years, the trend for new analytical strategies has aimed at maximizing the extraction and exhaustive identification of VOCs (omics-like) present in the sample. This design requires the optimization of careful methodology, including sample conservation and preparation. Several processes must be under control, like care extraction, concentration and analytical determination in order to obtain reliable and reproducible results. ${ }^{1}$ Solid phase microextraction (SPME) is one of the methodologies employed in recent years for determining

*e-mail: santiago@fcq.unc.edu.ar
VOCs in vegetable matrices, far exceeding other similar microextraction techniques. ${ }^{2}$ The advantages of using SPME, especially for headspace analysis, comprise its high sensitivity, simplicity, miniaturization, green chemistrytype, minimal sample pre-treatment, automation, as well as ability to measure solid, liquid and gaseous samples. ${ }^{3}$ In addition, SPME requires less sample preparation time. This methodology allows a simple sampling, extraction, concentration and sample introduction in one single step. SPME coupled to gas chromatography-flame ionization detector (GC-FID) or gas chromatography-mass spectrometry (GC-MS) shows excellent detection levels allowing the identification of a large number of VOCs in plant tissues and other biological matrices, including tomato fruits. ${ }^{4}$ For example, VOCs profiles achieved with SPME-GC-MS allowed differentiating 94 commercial tomato varieties, and also this was used to discriminate between regional and commercial tomatoes. ${ }^{5,6}$ 
The analysis of VOCs in tomato fruit has been studied for a long time, reporting to date approximately $400 \mathrm{VOCs}$ in different varieties of the cultivated species $S$. lycopersicum. ${ }^{7}$ Within this extensive list of VOCs, a small group of volatile metabolites is considered of fundamental importance due to its role in the development of the characteristic aroma of ripe fruit. ${ }^{8}$ Further, those VOCs reveal a correlation with health-promoting compounds and essential nutrients such as aminoacids and fatty acids. ${ }^{9}$ VOCs profile in tomato includes a large variety of molecules having low molecular weight, with extensive physicochemical characteristics, different functional groups and multiple metabolic origins. ${ }^{10}$

In the present study, we report on the use of headspace solid phase microextraction and gas chromatographymass spectrometry (HS-SPME-GC-MS) as a reliable methodology to determine the VOCs composition in tomato landraces that have been mainly selected for their good fruit quality and flavor by local farmers in Andean areas of Cuyo and Northwestern Argentina. ${ }^{11}$ This report is the first study of VOCs in local varieties of tomatoes from this geographical area, where their fruit metabolomic volatile profile is described and compared with the composition found in commercial varieties and in the wild ancestral and most related species $S$. pimpinellifolium.

\section{Experimental}

\section{Growing tomato plants}

Traditional tomatoes or landraces have been recovered recently in Andean areas of Cuyo and Northwestern
Argentina and maintained in the Horticulture Germplasm Bank of La Consulta Agricultural Experimental Station of the National Institute of Agropecuary Technology (INTA), Mendoza, Argentina (Table 1). These landraces have been evaluated and characterized by their agronomic performance, plant morphology and fruit quality traits. ${ }^{11}$

The VOCs composition was determined in selected tomato landraces (germplasm passport 4750, 3842, 565 and 557) considered as potential heirloom varieties. ${ }^{12,13}$ These Andean tomato landraces possess a diverse morphology compared with the standard plum-shaped fruit of the cultivable variety, M82 (germplasm passport 4735); 4750 accession have a regular brown-greenish cherry fruit, 557 accession have a red pear-shaped fruit, and 565 and 3842 accessions have large round-flattened, slightly segmented fruits (named Platense type in Argentina). These traditional tomatoes are also very prized for their intense flavor, flesh quality, color and texture. These important organoleptic characteristics allow considering Andean landraces and similar local varieties as valuable genomic reservoirs for improvement of future tomato cultivars with modern breeding techniques. ${ }^{14}$ One accession (LA1589, originally from C. M. Rick Tomato Genetics Resource Center, University of California, Davis, USA; Horticulture Germplasm Bank passport number 4739) of Solanum pimpinellifolium, a wild species closely related to cultivated tomatoes, was also included in this study.

Seeds were provided by the Horticulture Germplasm Bank. Plants were grown according to a random design with three replicates, in comparative field parcels of the Institute of Horticulture, Agronomy Faculty of the National

Table 1. Tomato varieties studied (2009)

\begin{tabular}{|c|c|c|c|c|c|c|}
\hline No. & Code & $\begin{array}{l}\text { Germplasm accession } \\
\text { passport No. }\end{array}$ & Species & Type & $\begin{array}{l}\text { Country, province } \\
\text { and locality }\end{array}$ & $\begin{array}{l}\text { Coordinates / } \\
\text { altitude }\end{array}$ \\
\hline 1 & LA1589 & 4739 & S. pimpinellifolium & cherry & $\begin{array}{c}\text { Peru, } \\
\text { La Libertad, } \\
\text { Viru-Galunga }\end{array}$ & $\begin{array}{c}8^{\circ} 23.3^{\prime} \mathrm{S} \\
78^{\circ} 44.3^{\prime} \mathrm{W}\end{array}$ \\
\hline 2 & M82 & 4735 & S. lycopersicum & plum & commercial & - \\
\hline 3 & $\mathrm{C} 237$ & 557 & S. lycopersicum & pear & $\begin{array}{l}\text { Argentina, } \\
\text { Salta, } \\
\text { Luracatao }\end{array}$ & $\begin{array}{c}25^{\circ} 22.2^{\prime} \mathrm{S} \\
66^{\circ} 26.0^{\prime} \mathrm{W} \\
2400 \mathrm{MASL}\end{array}$ \\
\hline 4 & TOPA & 3842 & S. lycopersicum & flattened & $\begin{array}{l}\text { Argentina, } \\
\text { Mendoza, } \\
\text { Las Heras }\end{array}$ & $\begin{array}{c}32^{\circ} 51^{\prime} \mathrm{S} \\
68^{\circ} 50^{\prime} \mathrm{W} \\
893 \mathrm{MASL}\end{array}$ \\
\hline 5 & $\mathrm{C} 352$ & 565 & S. lycopersicum & flattened & $\begin{array}{l}\text { Argentina, } \\
\text { Jujuy, } \\
\text { Patacal }\end{array}$ & $\begin{array}{c}23^{\circ} 42.0^{\prime} \mathrm{S} \\
65^{\circ} 31.9^{\prime} \mathrm{W} \\
2633 \mathrm{MASL}\end{array}$ \\
\hline 6 & CMP & 4750 & S. lycopersicum & cherry & $\begin{array}{l}\text { Argentina, } \\
\text { Mendoza, Luján }\end{array}$ & $\begin{array}{l}33^{\circ} 0.3^{\prime} \mathrm{S} \\
68^{\circ} 52.2^{\prime} \mathrm{W} \\
912 \mathrm{MASL}\end{array}$ \\
\hline
\end{tabular}

MASL: meters above sea level. 
University of Cuyo, Mendoza, Argentina (32 $50^{\prime} \mathrm{S}$, $68^{\circ} 52^{\prime} \mathrm{O}, 900$ meters above sea level). Mature fruits were harvested at the end of February 2009, in sunny days between 10:00 am and 16:00 pm in order to avoid variations in metabolism due to environmental light effects.

Fruit samples were selected fully red ripe (80 to $100 \%$ of the tomatoes revealed a uniform red coloration) with firm pericarp (should yield slightly to finger pressure), which is the mature stage normally preferred by people for fresh consumption. In all cases, six to ten different fruits from each landrace accession, commercial cultivars and the wild tomato species were harvested from three replicates, randomly distributed in the experimental parcel in order to avoid environmental effects. ${ }^{1}$ Harvested fruits were immediately transported in an icebox to the laboratory. Each fruit was immediately chopped, frozen in liquid nitrogen and stored in ultra-freezer at $-80{ }^{\circ} \mathrm{C}$ in individual plastic boxes until sample processing. Frozen samples were ground in an electrical mill previously cooled with liquid nitrogen until obtaining a homogeneous fine tomato powder. Grounded samples were stored in freezer at $-80^{\circ} \mathrm{C}$ in $50 \mathrm{~mL}$ polypropylene tube until sample analysis.

\section{Sample preparation}

Tomato powder $(1.0 \mathrm{~g})$ was placed in a polypropylene tube $(15 \mathrm{~mL})$ and immersed in a water bath at $35{ }^{\circ} \mathrm{C}$ for $10 \mathrm{~min}$. Next, $15 \mu \mathrm{L}$ of 2-methylcyclohexanone (internal standard dissolved in methanol at a concentration of $23 \mathrm{mg} \mathrm{L}^{-1}$ ) were added to the samples in addition to $1 \mathrm{~mL}$ ethylenediaminetetraacetic acid/sodium hydroxide (EDTA/NaOH) solution and $\mathrm{CaCl}_{2}(2.2 \mathrm{~g})$. EDTA/NaOH aqueous solution was prepared by adjusting $100 \mathrm{mM}$ EDTA to a $\mathrm{pH}=7.5$ with sodium hydroxide. Samples were sonicated for $15 \mathrm{~min}$. Then, $1 \mathrm{~mL}$ processed sample was transferred to a $10 \mathrm{~mL}$ screw-capped (magnetic cap) vial, fitted with a silicone septum. The vial was introduced in a Combi Pal (Varian Inc.) autosampler and conditioned $10 \mathrm{~min}$ at $50{ }^{\circ} \mathrm{C}$ with $500 \mathrm{rpm}$ shaking speed. After that, VOCs arising from the sample headspace were extracted using a SPME fiber assembly divinylbenzene/carboxen/polydimethylsiloxane (DVB/CAR/PDMS) (50/30 $\mu \mathrm{m}, 1 \mathrm{~cm}$ long from Supelco Ltd., Bellefonte, PA, USA) during $35 \mathrm{~min}$ at $50^{\circ} \mathrm{C}$ and with $250 \mathrm{rpm}$ shaking speed. Adsorbed VOCs were immediately desorbed at $250{ }^{\circ} \mathrm{C}$ in the injection port of the GC during $1 \mathrm{~min}$.

Analysis of volatile organic compounds (VOCs) using gas chromatography-mass spectrometry

VOCs were measured using gas chromatography coupled to mass spectrometry (GC-MS) by capillary GC
(Varian 3800 gas chromatograph equipped with a Varian VF-5ms column, $30 \mathrm{~m} \times 0.25 \mathrm{~mm}$ i.d. $1.00,0.25 \mu \mathrm{m}$ film thickness) and analyzed by MS using an ion trap detector (ITD-Varian $2000 \mathrm{MS}$ ). The SPME fiber was further heated for $3 \mathrm{~min}$ at $250{ }^{\circ} \mathrm{C}$ under nitrogen to avoid carry-over effect in the bake-out module. The MS trap temperature was set at $200{ }^{\circ} \mathrm{C}$, the manifold was heated at $100{ }^{\circ} \mathrm{C}$ and the transfer line at $230^{\circ} \mathrm{C}$ to avoid condensation of VOCs at the GC-MS interface. Electron impact mass spectra were recorded at $70 \mathrm{eV}$ ionization energy in the 33-300 amu mass range in scanning mode, with 1 scan per second. Oven temperature conditions were $35{ }^{\circ} \mathrm{C}$ for $5 \mathrm{~min}, 3{ }^{\circ} \mathrm{C} \mathrm{min}{ }^{-1}$ ramp until $45^{\circ} \mathrm{C}$ and $1.5^{\circ} \mathrm{C} \min ^{-1}$ ramp until $50^{\circ} \mathrm{C}$, held for $1.5 \mathrm{~min}$, $3{ }^{\circ} \mathrm{C} \mathrm{min}-1$ ramp until $68^{\circ} \mathrm{C}$, held for $2 \mathrm{~min}, 3{ }^{\circ} \mathrm{C} \mathrm{min}^{-1} \mathrm{ramp}$ until $131^{\circ} \mathrm{C}$, held for $1 \mathrm{~min}, 10^{\circ} \mathrm{C} \mathrm{m^{-1 }}$ ramp until $250{ }^{\circ} \mathrm{C}$, and then held isothermally at $250{ }^{\circ} \mathrm{C}$ for $2.93 \mathrm{~min}$ using helium 5.0 ultrapure carrier gas at $1 \mathrm{~mL} \mathrm{~min}^{-1}$. The runtime for a single chromatographic analysis was $58 \mathrm{~min}$. Mass spectra were analyzed with the Varian MS Workstation (Version 6.6) software.

Data analysis

The integrated area of each metabolite was normalized to the sample weight (1 g) in HS-SPME optimization. The area of a selected $\mathrm{m} / \mathrm{z}$ for a given VOCs (Ion area) was normalized to the sample weight $(1 \mathrm{~g})$ and the area of $m / z=112$ of the internal standard (Sti area) in order to obtain the final volatile profiles (equation 1). Data tables are in the Supplementary Information, Table S7.

Normalized area $=\left[\frac{\left(\frac{\text { Ion area }}{\text { Weight }}\right)}{\text { Sti area }}\right] \times 100$

VOCs data were processed and analyzed by univariate and multivariate statistical techniques. Significant differences were obtained on VOCs data applying an analysis of variance (ANOVA) using a significance level of $p<0.05$ and a mean comparison method, DGC. ${ }^{15}$ Multivariate data analysis was performed using principal component analysis (PCA) and discriminant analysis (DA). All statistical techniques were applied using the statistical software Infostat. ${ }^{16}$

\section{Results and Discussion}

\section{SPME optimization}

A mixture of 4 ripe fruits of commercial tomatoes purchased on the local market was processed for SPME 
optimization parameters. Some VOCs known in tomato were chosen to perform SPME optimization. The criterion for the best parameter extraction condition was the highest total average peak area and the minimal variation $(\mathrm{CV}, \%)$ of the selected VOCs. Based on a previous report, ${ }^{5}$ three commercially available SPME fibers, $75 \mu \mathrm{m}$ carboxen/ polydimethylsiloxane (CAR/PDMS: light blue), $65 \mu \mathrm{m}$ divinylbenzene/polydimethylsiloxane (DVB/PDMS: pink) and 50/30 $\mu \mathrm{m}$ DVB/CAR/PDMS (grey) were tested for extraction efficiency. Figure 1a summarizes average normalized areas of total selected compounds and standard deviation with different SPME fibers. Even though there are no significant differences between SPME fibers, the grey one shows higher absorption (Figure 1a) and the lowest individual analytical variability (CV $15.6 \%$, for more details see Supplementary Information, Table S1). Based on this, DVB/CAR/PDMS $(50 / 30 \mu \mathrm{m})$ (grey) was the fiber chosen to extract the volatile metabolites from tomato.

Having selected the fiber (DVB/CAR/PDMS), the effect of extraction time change was assessed. The extraction was performed during 30,40 and 50 minutes, at $30{ }^{\circ} \mathrm{C}$ under constant shaking. As shown in Figure 1b, higher area values are obtained at 30 or 40 minutes. In general, VOCs of lower molecular weight have higher area values at
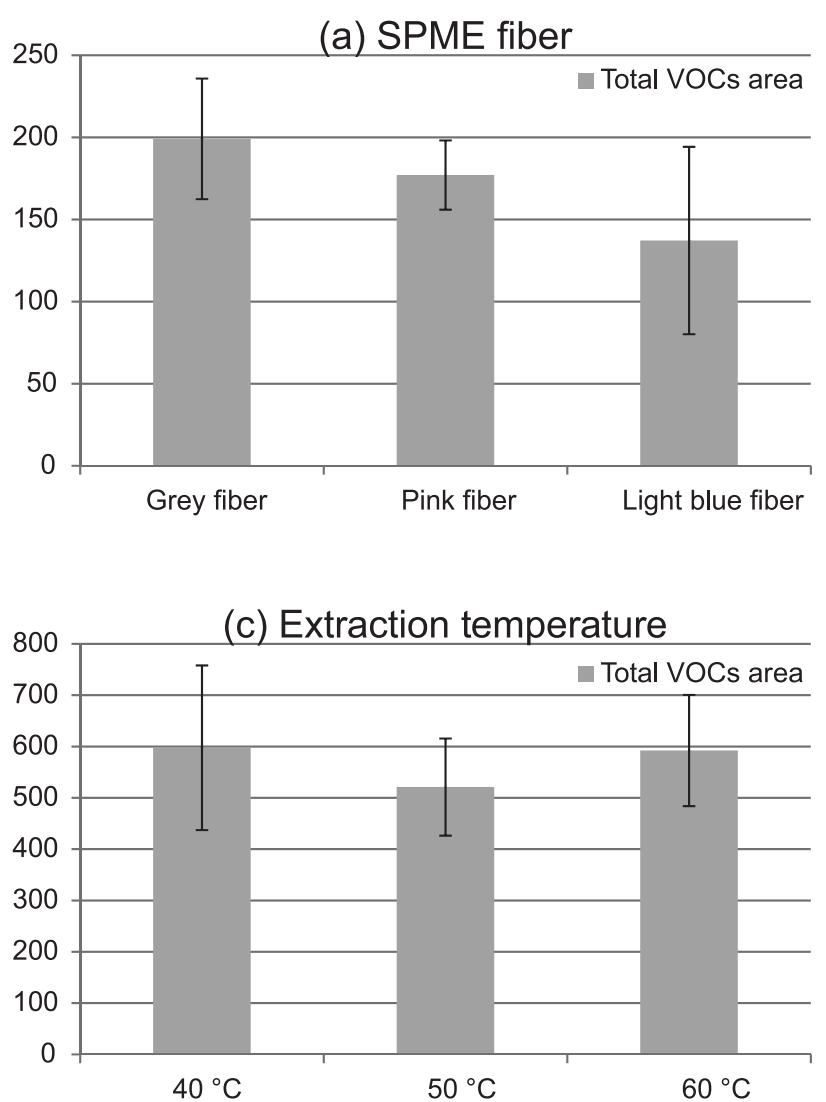

short times; instead, VOCs of higher molecular weight have higher area values at longer extraction times (for further details see Supplementary Information, Table S2). Given the chemical nature of the VOCs, the small difference in area between 30 and 40 minutes, and the need for a shorter analysis time due to the number of samples, it was decided that 35 minutes was the most convenient extraction time.

The next experimental parameter analyzed was extraction temperature of VOCs in the fiber. Using the previously selected parameters ((DVB/CAR/PDMS) fiber and 35 minutes of extraction time), the optimal temperature was assessed. The extraction was performed at: 40,50 and $60{ }^{\circ} \mathrm{C}$ (Figure 1c). It should be noted that no significant differences were observed between measurements done at the three different temperatures when total area analysis was considered. However, small metabolites at lower temperatures reached higher concentrations in a shorter time in the headspace. Instead, high molecular weight VOCs needed higher temperatures to produce a significant measurement. Using the intermediate temperature of $50^{\circ} \mathrm{C}$, a lower variability and a more elevated area of small and high molecular weight metabolites were observed (CV 18.2 against $26.2 \%$, for more details see Supplementary Information, Table S3). Based on this phenomenon, $50^{\circ} \mathrm{C}$
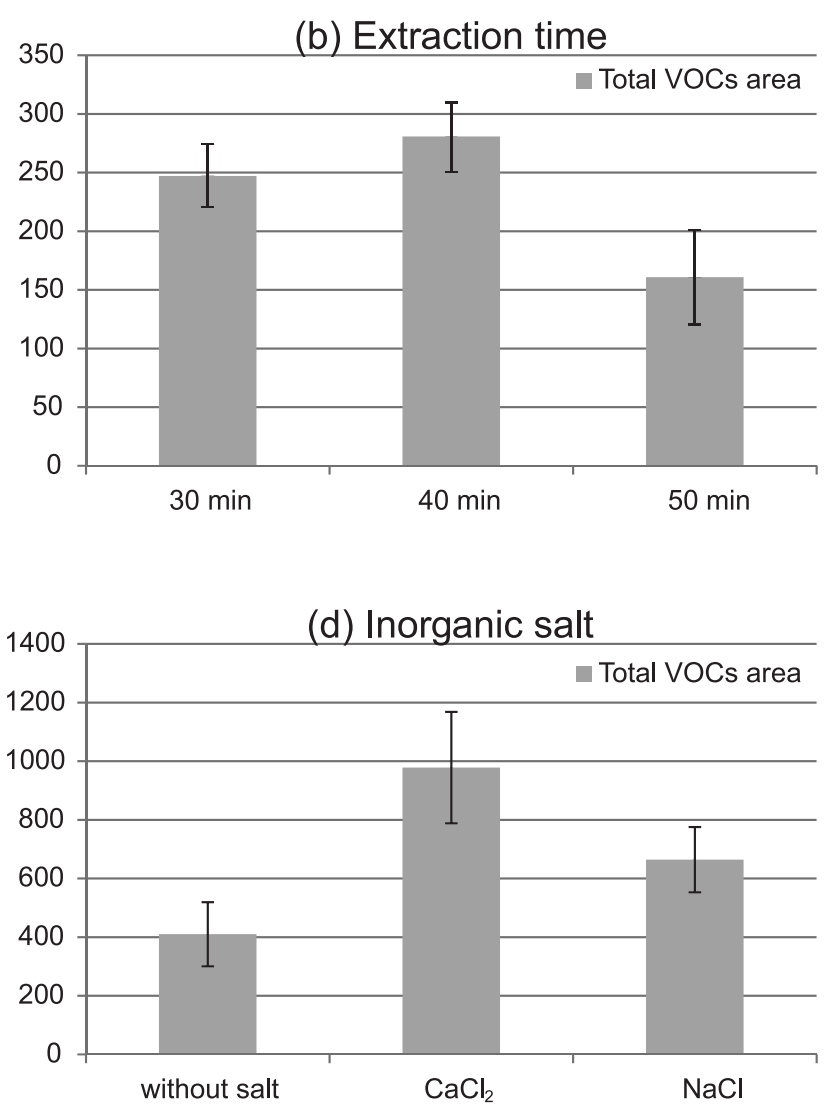

Figure 1. Average areas of: (a) VOCs extracted with different SPME fibers; (b) VOCs extracted at different times; (c) VOCs extracted at different temperatures; (d) VOCs extracted with different inorganic salts (total average areas expressed as $10^{4}$ ). 
was selected to produce the best combined result in order to achieve good signal areas for the diverse chemical nature of the selected VOCs.

One of the most important challenges in the analysis of VOCs in biological matrices is to obtain a stable profile, because they can undergo transformation due to enzymatic and non-enzymatic reactions. ${ }^{17}$ The addition of inorganic salts in these matrices promotes precipitation of proteins, changing the ionic strength in the medium (salting out) and increasing the concentration of VOCs in the vapor phase. ${ }^{18}$ Sodium chloride is commonly used due to their low interference with VOCs, however in complex matrices such as tomato, $\mathrm{CaCl}_{2}$ is often used since it promotes the reduction of enzyme activity and generates the effect of salting out. ${ }^{8}$ In addition, Tikunov et al. ${ }^{5}$ reported the necessity of adding to the matrix a solution of ethylenediaminetetraacetic acid (EDTA) dissolved in sodium hydroxide. This addition causes two effects: firstly the inclusion of a chelating agent to reduce the action of certain metalloenzymes and secondly the increase in the matrix $\mathrm{pH}$. Considering the physiological $\mathrm{pH}$ of the fruit (close to 4-4.5), lower acidity aims at reducing the enzyme action and decreasing the non-enzymatic oxidation of labile functional groups. In addition to the desirable effect of maximizing VOCs concentration in the headspace, some divalent salt can interact with specific functional groups, like thiazole, reducing the availability of interacting with the SPME fiber polymer. ${ }^{16}$

Hereby, the addition of inorganic salt and EDTA was assayed, using the best extracting fiber (DVB/CAR/PDMS), the optimal extraction temperature $\left(50^{\circ} \mathrm{C}\right)$ and the optimal extraction times (35 min). The extraction was performed using $1 \mathrm{~g}$ of sodium chloride, $1 \mathrm{~g}$ of $\mathrm{CaCl}_{2}$ and no salt. As Figure 1d shows, the highest total peak area was achieved using $\mathrm{CaCl}_{2}$ and the lowest was without salt addition (for further details see Supplementary Information, Table S4). Considering the best result achieved, $\mathrm{CaCl}_{2}$ was selected to enhance the VOCs extraction. Next, it was also necessary

(a) $\mathrm{CaCl}_{2}$ amount

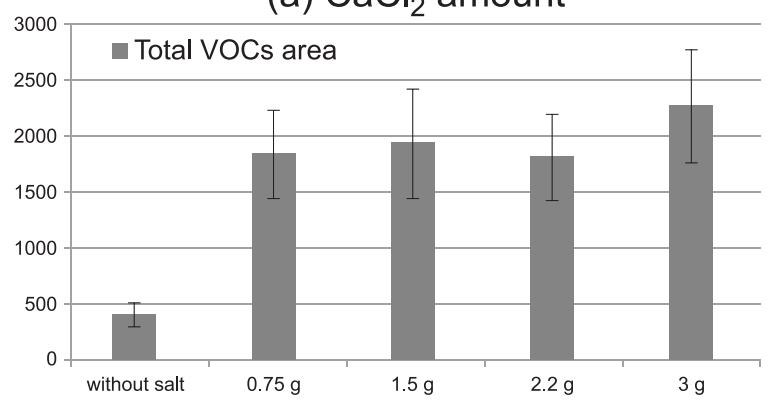

to determine the amount of $\mathrm{CaCl}_{2}$ to be used. Hence, the extraction assay was performed using $0.75,1.5,2.2$ and $3 \mathrm{~g}$ of $\mathrm{CaCl}_{2}$ (Figure 2a). As Figure 2a shows, no significant differences in total peak area were observed between measurements. However, different $\mathrm{CaCl}_{2}$ quantities produced changes in the individual areas of some VOCs. When a large amount of $\mathrm{CaCl}_{2}$ was used ( $3 \mathrm{~g}$ or above), a more orderly aggregation state of the sample matrix was obtained and some selected VOCs could not be observed at this experimental assay. ${ }^{19}$ This sample condition, as a very viscous liquid, hinders the promotion of VOCs to the headspace. On the other hand, when the minimum amount was used $(0.75 \mathrm{~g})$, almost all the individual areas of the VOCs decreased (for further details see Supplementary Information, Table S5). Therefore, 1.5 and $2.2 \mathrm{~g}$ of $\mathrm{CaCl}_{2}$ were chosen as the best conditions with minimal differences.

Finally, using the best extracting conditions, the addition of EDTA was assayed. A solution $100 \mathrm{mM}$ of EDTA in $\mathrm{NaOH}$ at $\mathrm{pH}=7.5$ was employed. Two amounts of $\mathrm{CaCl}_{2}$ $(1.5$ or $2.2 \mathrm{~g}$ ) combined with $1 \mathrm{~mL}$ of EDTA or without EDTA were used to optimize the best condition. As Figure $2 \mathrm{~b}$ shows, no significant differences were observed between measurements when total area analysis was considered. Moreover, a decrease in the individual compound areas was determined using EDTA, probably due to sample dilution on matrix (Supplementary Information, Table S6). Despite this, EDTA solution was used, since a reduction in analytical variability was observed. In addition, previous work ${ }^{20}$ proposed that a dilution in sample matrix also favors the dilution of possible interferences, such as suspension fruit pulp, producing an accurate VOCs recovery. Hence, $2.2 \mathrm{~g} \mathrm{CaCl}_{2}$ with $1 \mathrm{~mL}$ EDTA solution was chosen as the best condition.

Based on the best parameters obtained, the SPME optimized protocol for VOCs extraction of tomato was: DVB/CAR/PDMS SPME fiber, $50{ }^{\circ} \mathrm{C}$ extraction temperature, 35 min extraction time, $2.2 \mathrm{~g} \mathrm{CaCl}_{2}$ with

\section{(b) EDTA solution}

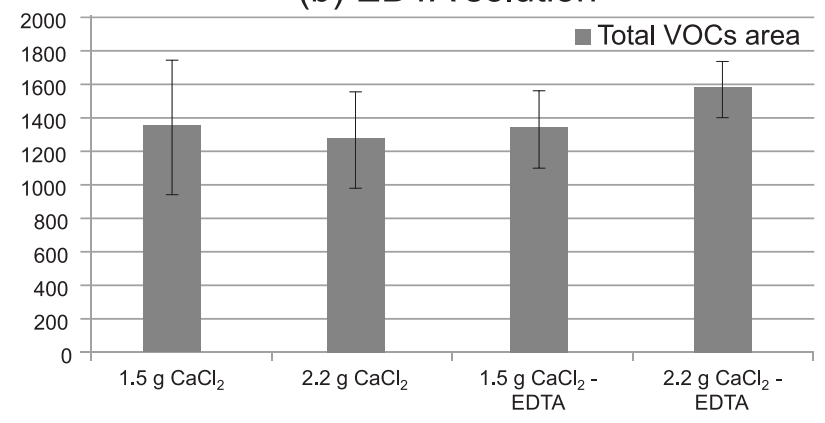

Figure 2. (a) Average areas of VOCs extracted with different $\mathrm{CaCl}_{2}$ amount; (b) average areas of VOCs extracted with 1.5 or $2.2 \mathrm{~g}$ of CaCl 2 without EDTA or with $1 \mathrm{~mL}$ of EDTA in $\mathrm{NaOH}$ (total average areas expressed as $10^{4}$ ). 
$1 \mathrm{~mL}$ EDTA/NaOH solution. The optimized extraction protocol was used to study the VOCs of Andean tomato landraces from Argentina. A mixture of the different tomatoes included in this study was performed to adjust the chromatographic method and allow reducing signal overlapping in a complex chromatogram. The profile consisted of 101 signals of volatile metabolites; it was identified considering both retention times against known standard and mass spectral match with NIST MS library. VOCs were quantified using a relative internal standard and are expressed as relative area units per $\mathrm{g}$ fruit (fresh weight). Signals designated as UNK could not be assigned to a definitive structure. Despite extensive and optimized chromatographic program used to resolve complex co-elution zones, it was necessary to employ extracted ion chromatogram (EIC) in order to quantify signals of interest. ${ }^{21}$ EIC simplifies the quantification of all the VOCs along a complex chromatogram using a specific relation of $\mathrm{m} / \mathrm{z}$ for each signal of interest (Table 2). This methodology has been used to facilitate the screening of a large amount of VOC with excellent results. For example, EIC was used to determine pesticide residues and volatile metabolites in tomato fruits. ${ }^{5,6,22}$ Table 2 shows the signals and the ions of VOCs determined in the HS-SPME-GC-MS analysis in tomato. Codes were assigned to each metabolite in order to facilitate study.

Table 2. Volatile metabolites extracted by HS-SPME-GC-MS

\begin{tabular}{|c|c|c|c|c|c|}
\hline Signal & $\mathrm{RT}$ & Name & CAS & $\mathrm{m} / \mathrm{z}$ & Code \\
\hline- & 17.294 & 2-methylcyclohexanone & $583-60-8$ & 112 & Std \\
\hline 1 & 2.753 & 2-methylfuran & $534-22-5$ & 82 & M1 \\
\hline 2 & 2.768 & $\mathrm{UNK} m / z 43$ & & 43 & M2 \\
\hline 3 & 3.571 & 3-methylbutanal & $590-86-3$ & 58 & M3 \\
\hline 4 & 3.996 & 1-penten-3-one & $1577-03-3$ & 55 & M4 \\
\hline 5 & 4.266 & 2-ethylfuran & $3208-16-0$ & 96 & M5 \\
\hline 6 & 4.947 & methyl butanoate & $623-42-7$ & 74 & M6 \\
\hline 7 & 5.691 & 3-methyl-1-butanol & $123-51-3$ & 55 & M7 \\
\hline 8 & 6.065 & $\mathrm{UNK} m / z 55$ & & 55 & M8 \\
\hline 9 & 6.192 & cis, cis-1,4-pentadiene & $591-93-5$ & 68 & M9 \\
\hline 10 & 6.306 & trans-4-pentenal & $2100-17-6$ & 83 & M10 \\
\hline 11 & 6.514 & toluene & $108-88-3$ & 91 & M11 \\
\hline 12 & 7.325 & cis-3-hexenal & $6789-80-3$ & 69 & M12 \\
\hline 13 & 7.406 & hexanal & $66-25-1$ & 56 & M13 \\
\hline 14 & 10.674 & cis-2-hexenal & $16635-54-4$ & 55 & M14 \\
\hline 15 & 11.258 & trans-2-hexenal & $6728-26-3$ & 55 & M15 \\
\hline 16 & 14.255 & heptanal & $111-77-7$ & 70 & M16 \\
\hline 17 & 14.398 & 1-nitropentane & $628-05-7$ & 55 & M17 \\
\hline 18 & 15.037 & $\alpha$-pinene & $7785-70-8$ & 93 & M18 \\
\hline 19 & 15.753 & limonene oxide & $203719-54-4$ & 67 & M19 \\
\hline 20 & 15.800 & $\mathrm{UNK} m / z 83$ & & 83 & M20 \\
\hline 21 & 16.334 & $p$-methoxytoluene & $3494-45-9$ & 122 & M21 \\
\hline 22 & 16.800 & $\mathrm{UNK} m / z$ 93-1 & & 93 & M22 \\
\hline 23 & 17.700 & $\mathrm{UNK} m / z$ 93-2 & & 93 & M23 \\
\hline 24 & 18.277 & trans-2-heptenal & $18829-55-5$ & 55 & M24 \\
\hline 25 & 18.581 & geranic oxide & $7392-19-0$ & 139 & M25 \\
\hline 26 & 19.079 & benzaldehyde & $100-57-7$ & 105 & M26 \\
\hline 27 & 19.216 & methyl trimethoxy acetate & $598-98-1$ & 75 & M27 \\
\hline 28 & 20.009 & 6-methyl-5-hepten-2-one & $110-93-0$ & 108 & M28 \\
\hline 29 & 20.100 & 2-pentylfuran & $3777-69-3$ & 81 & M29 \\
\hline 30 & 20.512 & isoterpinolene & $586-63-0$ & 136 & M30 \\
\hline 31 & 20.713 & $\mathrm{UNK} m / z$ 57-1 & & 57 & M31 \\
\hline 32 & 20.853 & 6-methyl-5-hepten-2-ol & $1569-60-4$ & 69 & M32 \\
\hline 33 & 21.192 & octanal & $124-13-0$ & 81 & M33 \\
\hline 34 & 22.353 & $\mathrm{UNK} m / z 105$ & & 105 & M34 \\
\hline 35 & 22.843 & limonene & $138-86-3$ & 68 & M35 \\
\hline 36 & 23.362 & 2-ethyl-1-hexanol & 104-76-7 & 83 & M36 \\
\hline
\end{tabular}


Table 2. Volatile metabolites extracted by HS-SPME-GC-MS (cont.)

\begin{tabular}{|c|c|c|c|c|c|}
\hline Signal & RT & Name & CAS & $m / z$ & Code \\
\hline 37 & 23.395 & 2-isobutylthiazole & $18640-74-9$ & 99 & M37 \\
\hline 38 & 24.568 & 2-octenal & $2548-87-0$ & 83 & M38 \\
\hline 39 & 24.800 & phenylacetaldehyde & $122-78-1$ & 91 & M39 \\
\hline 40 & 25.832 & cis-linalyl oxide & $11063-77-7$ & 59 & M40 \\
\hline 41 & 26.697 & terpinolene & $586-65-9$ & 136 & M41 \\
\hline 42 & 26.813 & trans-linalyl oxide & $68780-91-6$ & 59 & M42 \\
\hline 43 & 27.276 & $\mathrm{UNK} m / z 58$ & & 58 & M43 \\
\hline 44 & 27.373 & 2-methyl-3-phenyl-1-propene & $3290-53-7$ & 132 & M44 \\
\hline 45 & 27.700 & guaiacol & $9009-62-5$ & 124 & M45 \\
\hline 46 & 27.956 & linalool & $78-70-6$ & 93 & M46 \\
\hline 47 & 28.296 & 2-nonen-1-ol & $31502-14-4$ & 67 & M47 \\
\hline 48 & 28.524 & 2-methylacetophenone & $577-16-2$ & 119 & M48 \\
\hline 49 & 29.201 & $\alpha$-isophorone & $78-59-1$ & 82 & M49 \\
\hline 50 & 30.088 & 2-phenylethanol & $60-12-8$ & 91 & M50 \\
\hline 51 & 30.426 & camphor & $8031-27-4$ & 95 & M51 \\
\hline 52 & 30.587 & 3-methylheptylacetate & $72218-58-7$ & 43 & M52 \\
\hline 53 & 30.864 & $\mathrm{UNK} m / z 120$ & & 120 & M53 \\
\hline 54 & 31.379 & benzylnitrile & $100-47-0$ & 117 & M54 \\
\hline 55 & 31.857 & benzylacetate & $140-11-4$ & 108 & M55 \\
\hline 56 & 32.335 & $\mathrm{UNK} m / z 94$ & & 94 & M56 \\
\hline 57 & 32.754 & DMHEX & $70786-44-6$ & 137 & M57 \\
\hline 58 & 32.904 & $\alpha$-terpineol & $98-55-5$ & 136 & M58 \\
\hline 59 & 33.182 & decanal & $112-31-2$ & 83 & M59 \\
\hline 60 & 33.400 & methyl salycilate & $119-36-8$ & 152 & M60 \\
\hline 61 & 33.415 & UNK $m / z 119$ & & 119 & M61 \\
\hline 62 & 34.637 & $p$-menth-1-en-9-al & 29548-14-9 & 94 & M62 \\
\hline 63 & 34.911 & dimethylbenzaldehyde & $5779-94-2$ & 133 & M63 \\
\hline 64 & 33.316 & UNK $m / z 57-2$ & & 57 & M64 \\
\hline 65 & 35.707 & $\beta$-citral & $5392-40-5$ & 69 & M65 \\
\hline 66 & 36.159 & carvone & $99-49-0$ & 82 & M66 \\
\hline 67 & 36.641 & 2-phenylethylacetate & $103-45-7$ & 104 & M67 \\
\hline 68 & 36.941 & 2-decenal & 3913-71-1 & 70 & M68 \\
\hline 69 & 37.239 & $\alpha$-citral & $96680-15-8$ & 69 & M69 \\
\hline 70 & 38.238 & 2-undecanone & $112-12-9$ & 58 & M70 \\
\hline 71 & 38.579 & trans,trans-2,4-decadienal & $25152-84-5$ & 81 & M71 \\
\hline 72 & 38.856 & 2-undecanol & $1663-30-1$ & 45 & M72 \\
\hline 73 & 39.003 & duraldehyde & $5779-72-6$ & 147 & M73 \\
\hline 74 & 39.373 & UNK $m / z, 57-3$ & & 57 & M74 \\
\hline 75 & 39.624 & (3E)-4-methyl-3-hepten-2-one & $22319-25-1$ & 111 & M75 \\
\hline 76 & 40.570 & $\mathrm{UNK} m / z 95$ & & 95 & M76 \\
\hline 77 & 40.800 & eugenol & $97-53-0$ & 164 & M77 \\
\hline 78 & 41.337 & TRIMCICL & $16695-72-0$ & 163 & M78 \\
\hline 79 & 41.911 & $\mathrm{UNK} m / z 161$ & & 161 & M79 \\
\hline 80 & 42.168 & $\beta$-damascenone & $23696-85-7$ & 69 & M80 \\
\hline 81 & 42.345 & 2-methyl-2-octen-4-one & 19860-71-0 & 83 & M81 \\
\hline 82 & 42.781 & $\mathrm{UNK} m / z 68$ & & 68 & M82 \\
\hline 83 & 44.071 & verdyl acetate & $5413-60-5$ & 66 & M83 \\
\hline 84 & 44.360 & $\mathrm{UNK} m / z, 147$ & & 147 & M84 \\
\hline 85 & 44.923 & geranyl acetone & $689-67-8$ & 43 & M85 \\
\hline 86 & 45.297 & 2,5-ditertbutylbenzoquinone & $2460-77-7$ & 177 & M86 \\
\hline 87 & 45.379 & lilial & $80-54-6$ & 189 & M87 \\
\hline 88 & 45.684 & $\mathrm{UNK} m / z, 131$ & & 131 & M88 \\
\hline
\end{tabular}


Table 2. Volatile metabolites extracted by HS-SPME-GC-MS (cont.)

\begin{tabular}{|c|c|c|c|c|c|}
\hline$\underline{\text { Signal }}$ & RT & Name & CAS & $\mathrm{m} / \mathrm{z}$ & Code \\
\hline 89 & 45.847 & $\beta$-ionone & $14901-07-6$ & 177 & M89 \\
\hline 90 & 45.960 & $\beta$-ionone epoxide & $23267-57-4$ & 123 & M90 \\
\hline 91 & 46.171 & 2-dodecanone & $6175-49-1$ & 85 & M91 \\
\hline 92 & 46.284 & 1-phenyl-1-propanol & $93-54-9$ & 107 & M92 \\
\hline 93 & 46.299 & ar-himachalen-2-ol & $119660-66-1$ & 203 & M93 \\
\hline 94 & 46.766 & propyl salicylate & $607-90-9$ & 120 & M94 \\
\hline 95 & 46.864 & UNK $m / z 115$ & & 115 & M95 \\
\hline 96 & 47.609 & isoamyl salicylate & $87-20-7$ & 120 & M96 \\
\hline 97 & 48.189 & pseudoionone & $141-10-6$ & 69 & M97 \\
\hline 98 & 48.880 & $\beta$-methylionone & $127-43-5$ & 191 & M98 \\
\hline 99 & 49.188 & benzophenone & $119-61-9$ & 182 & M99 \\
\hline 100 & 49.418 & 8-pentadecanone & $818-23-5$ & 57 & M100 \\
\hline 101 & 50.638 & $\alpha$-hexylcinnamaldehyde & $101-86-0$ & 129 & M101 \\
\hline
\end{tabular}

std: 2- methylcyclohexanone added as internal standard; signal 25: 2,6,6-trimethoxy-2-vinyltetrahidropyrane; signal 57: 3,6-dimethyl-2,3,3a,4,5,7ahexahidrobenzofurane; signal 78: (1E)-1-(3,5,5-trimethyl-2-cyclohexen-1-ylidene)-2-propanone; RT: retention time; $m / z$ : quantification ion.

\section{HS-SPME-GC-MS tomato VOCs profile}

VOCs profiles of different tomato samples obtained with the optimized protocol showed a variable metabolic composition. Figure 3 shows the chromatographic comparison between S. lycopersicum and S. pimpinellifolium tomato species. As can be seen, there is a noticeable difference on the volatile profile of the analyzed fruits.

Particularly, the wild species (4739), S. pimpinellifolium, showed the highest number of VOCs derived from fatty acids. Among S. lycopersicum varieties, the accessions
565 and 3842 showed the highest contribution of VOCs derived from aromatic amino acid and an equal contribution of VOCs derived from apocarotenoids and fatty acid (see Supplementary Information, Table S8).

Volatile compounds which have not been previously reported in tomato were identified in volatile profiles (see Supplementary Information, Table S8). Novel VOCs associated with the wild species 4739 were cis, cis1,4-pentadiene, cis-4-pentenal, 2-methyl-3-phenyl-1propene, 2-methylacetophenone, DMHEX: 3,6-dimethyl2,3,3a,4,5,7a-hexahidrobenzofurane and 1-phenyl-1-

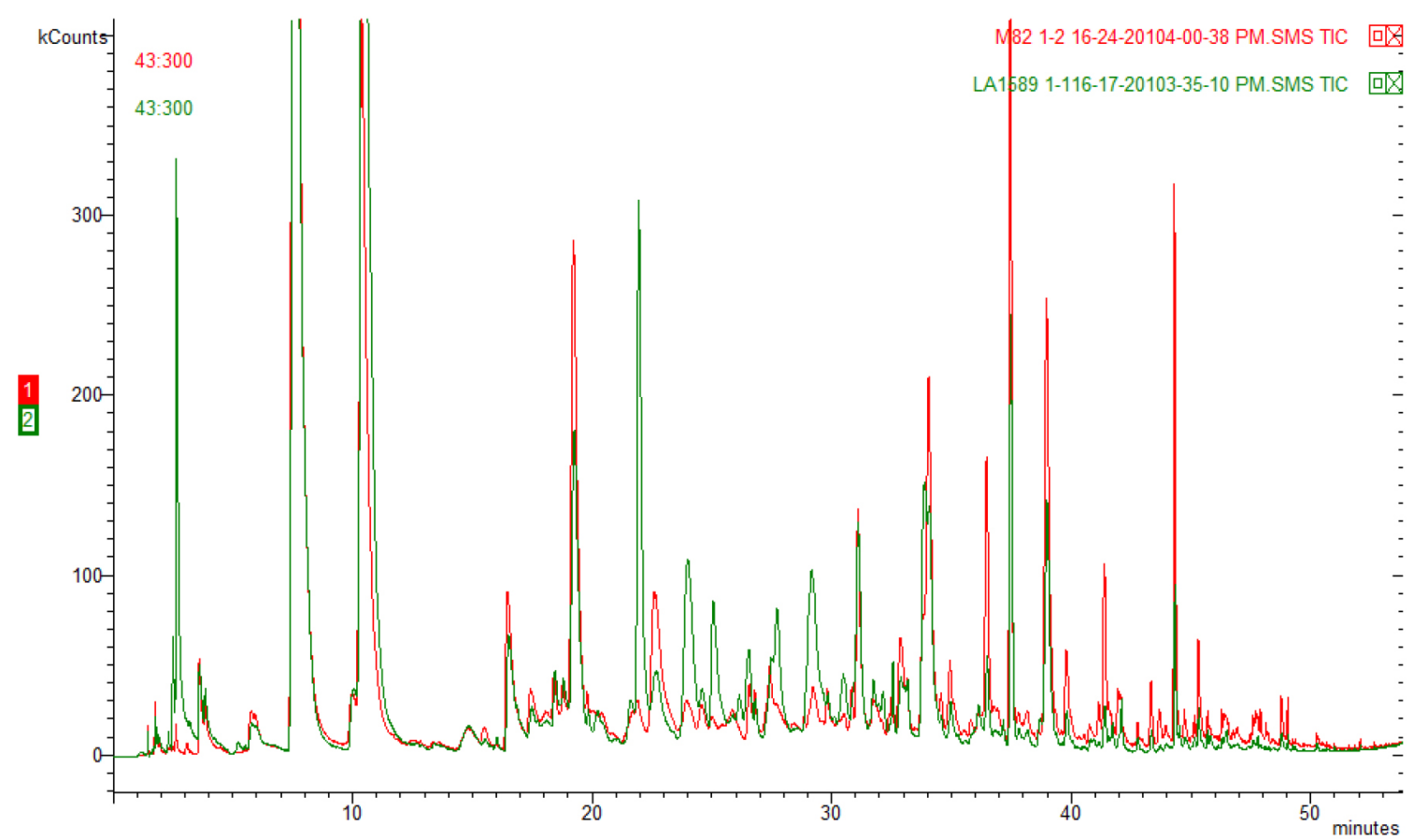

Figure 3. Chromatographic comparison of two tomato species. In red chromatogram: M82 (No. 4735, S. lycopersicum) and green chromatogram: LA1589 (No. 4739, S. pimpinellifolium). 
propanol (Supplementary Information, Table S9).

Other novel compounds were more related to the S. lycopersicum landraces. For example, geranic oxide and lilial were more expressed in accessions 4750 and 557. By contrast, accessions 565 and 3842 showed higher levels of the novel volatile compounds. They were 3-methylheptyl acetate, duraldehyde, (3E)-4-methyl-3hepten-3-one, TRIMCICL: (1E)-1-(3,5,5-trimethyl-2cyclohexen-1-ylidene)-2-propanone, 2-methyl-2-octen-4one, verdyl acetate, ar-himachalen-2-ol, propyl salicylate, isoamyl salicylate, $\beta$-methyl ionone, benzophenone, 8 -pentadecanone and $\alpha$-hexyl cinnamaldehyde (Supplementary Information, Table S9).

In a few words, 21 novel volatile compounds could be identified in tomatoes analyzed by an exhaustively optimized method of HS-SPME coupled to GC-MS (Figure 4). It should be mentioned that using SPME for extraction of VOCs has many advantages which help to avoid possible derivatization of VOCs (low temperature, addition of additives) and that the conditions used in the present study were similar to those reported by other authors. ${ }^{5,6,23}$

Taking into consideration the flavor quality of the Andean landraces, these results provide new VOCs as potential candidates involved in the good flavor perception of tomato fruit. In addition, it is well known that more abundant VOCs no necessarily contribute to the characteristic tomato flavor; ${ }^{24}$ hence, these new VOCs must be more intensely studied to be considered relevant in the complex chemistry trivia associated with tomato flavor perception.

\section{Chemometric study of Andean tomato VOCs profile}

Data obtained from HS-SPME-GC-MS studies were subjected to principal component analysis (PCA) (Figures 5 and 6). PCA is a multivariate statistical technique

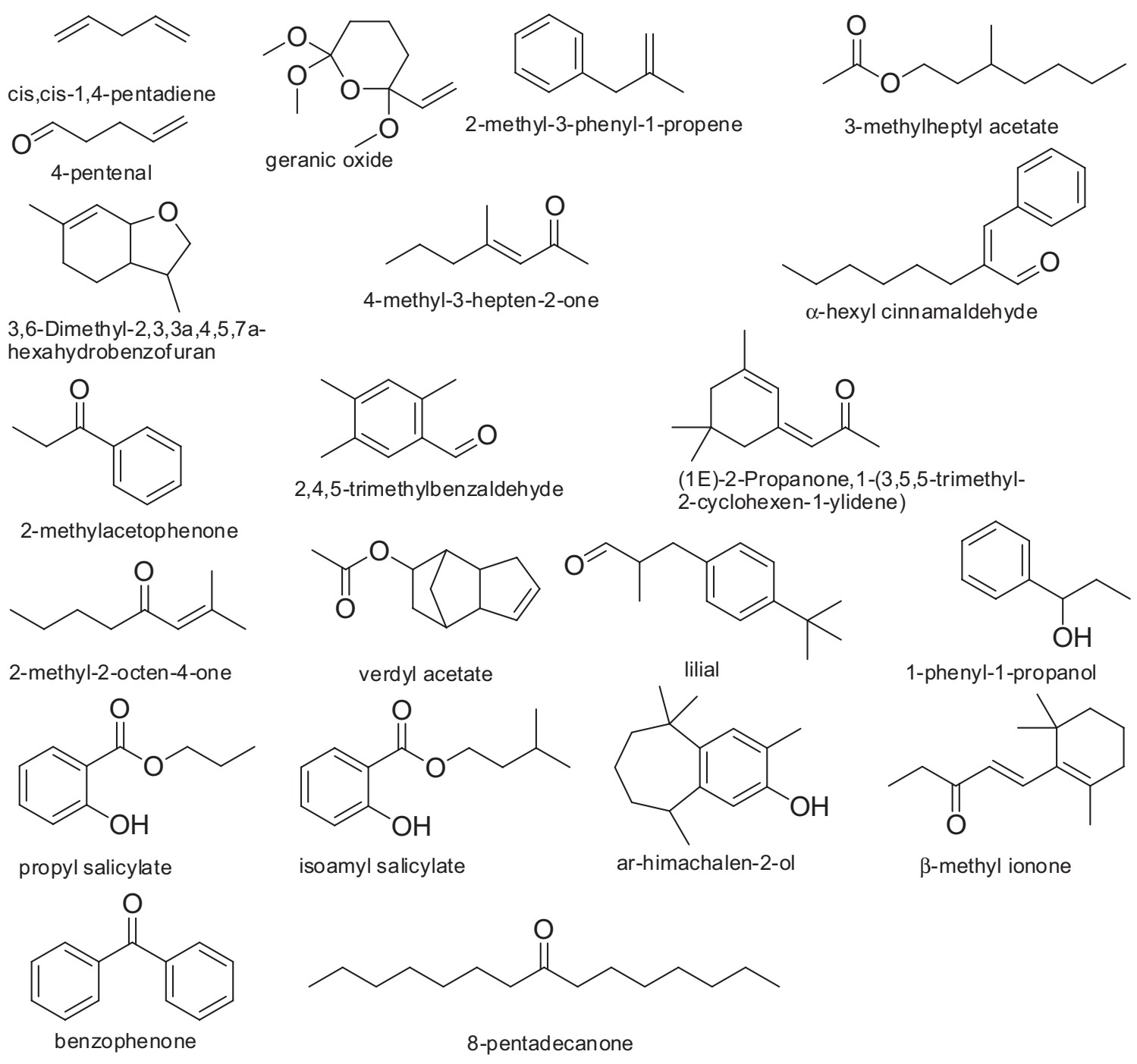

Figure 4. Structures of novel tomato VOCs proposed. 
commonly used to provide a better visualisation of a large data matrix, such as VOCs profile..$^{25}$ In the present study, the PCA permitted to observe relationships and differences between tomatoes. Specifically, the chemometric analysis allowed observing the grouping of three different sets of tomatoes. The wild species (4739) stood separately from all $S$. lycopersicum varieties. Furthermore, two Andean landraces (4750 and 557) had a closer relation to the cultivable variety, 4735 (M82), while the landraces 3842 and 565 differed from the last group mentioned.

The first two principal components (PC1 and PC2) explain the $59 \%$ of total variability, showing a good differentiation between tomato samples (Figure 5). PC1 separates the three main tomato groups in the biplot in accordance with tomato morphology (cherry, plum, flattened). The cherry wild tomato 4739 and cherry Andean landrace 4750 were differentiated from the others groups due to their characteristic volatile profile. Andean tomato landraces 565 and 3842, with large round-flattened and slightly segmented multilocular fruits, were separated from the central group containing the pear tomato landrace 557 and the plum tomato commercial variety 4735 , mainly used for processing. In addition, $\mathrm{PC} 2$ allowed differentiating the wild red cherry 4739 from the brown-greenish cherry 4750 and the two flattened tomatoes 565 from 3842.

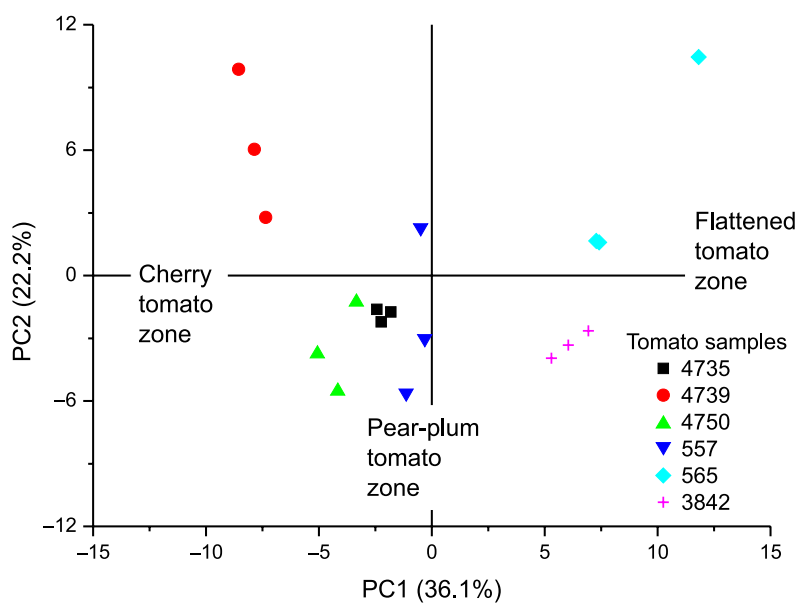

Figure 5. Principal components analysis scores scatter plot of Andean tomato landraces, modern edible cultivar (4735) and S. pimpinellifolium (4739).

VOCs that most contributed to group separation in PC1 (Figure 6) and were more related to 4739 and 4750 (cherry group) were M16 (heptanal), M20 (UNK $m / z$ 83), M24 (trans-2-heptenal), M40 (cis-linalyl oxide), M42 (trans-linalyl oxide), M49 ( $\alpha$-isoforone), M66 (carvone), M6 (methyl butanoate), M14 (cis-2-hexenal), M10 (4-pentenal), M7 (3-methyl-1-butanol) and M57 (DMHEX: 3,6-dimethyl-2,3,3a,4,5,7a-hexahidrobenzofurane).

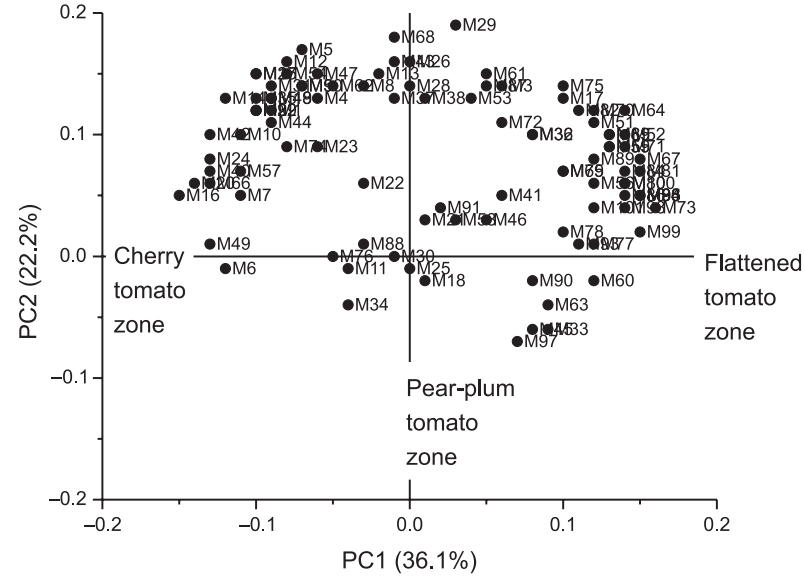

Figure 6. Principal components analysis loading weight plot of Andean tomato landraces, modern edible cultivar (4735) and S. pimpinellifolium (4739).

The volatile compounds more related with flattened fruit Andean landraces, differing from the commercial tomato 4735, were M67 (2-phenyethyl acetate), M81 (2-methyl-2-octen-4-one), M83 (verdyl acetate), M94 (propyl salicylate), M95 (UNK $\mathrm{m} / \mathrm{z}$ 115), M96 (isoamyl salicylate), M99 (benzophenone), M73 (duraldehyde), M100 (8-pentadecanone), M98 ( $\beta$-methyl ionone), M86 (2,5-ditertbutylbenzoquinone), M84 (UNK $m / 2$ 147), M80 ( $\beta$-damascenone), M71 (trans,trans-2,4-decadienal) and M64 (UNK $m / z 57-2$ ). As can be seen in the loading weight plot (Figure 6), tomatoes 565 and 4739 showed the presence of more VOCs due to their high concentration on the fruits.

Concerning flavor-related volatiles ${ }^{8,9}$ in the PCA, they were distributed mainly in two areas (cherry tomato and flattened tomato). The central zone (pear-plum tomatoes) contained no VOCs associated with the characteristic flavor of the fruit. However, in this area some landraces of good sensory acceptance were located. This makes us think that other VOCs, different from the characteristic ones, can contribute to a good sensory evaluation of fruit. These results are consistent with the Tiemann's theory, which suggests that not only the historically accepted flavor-related volatiles contribute to the aroma of tomato. ${ }^{5}$

The multivariate analysis of VOCs profiles showed the metabolic differences between related tomato species, noncommercial regional accessions and a commercial variety of S. lycopersicum. Andean landraces exhibited richer VOCs content and higher amounts of novel compounds than those with the commercial variety (Supplementary Information, Table S10).

On the other hand, using only the 21 novel VOCs described, discriminant analysis (DA) was performed. The multivariate analysis allowed discriminating and classifying a set of objects based on the significant differences of multiple variables. The results of DA showed a correct 
classification of the six tomato samples (Figure 7 and see Supplementary Information, Table S10).

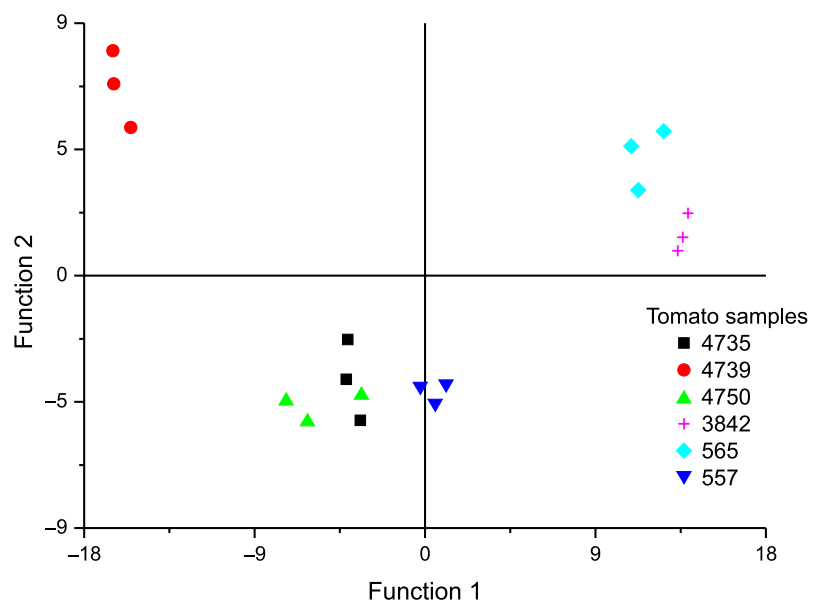

Figure 7. Discriminant analysis scatter plot of four Andean tomato landraces, modern edible cultivar (4735) and S. pimpinellifolium accession (4739).

The first discriminant function explains the correct grouping of fruits of the same accession. Only the Andean landrace 4750 presented more similarity to the commercial variety 4735 . In a similar way to PCA, the grouping of samples on DA maintains the observed relationship to the fruit shape.

Finally, the multivariate classification process presented a satisfactory result based on a few characteristic volatile compounds. The 21 novel VOCs are sufficient to discriminate among the tomato samples.

\section{Conclusion}

The results presented here involve the optimization of HS-SPME extraction parameters, GC-MS-EIC quantification and chemometric analysis of VOCs profile of Andean tomato landraces. The study reports 21 new VOCs used to perform a statistical classification of tomato fruits. The valuable metabolic information presented could be used in future studies on the discovery of new enzymatic processes within known biological pathways impacting on tomato flavor. ${ }^{14}$ Moreover, taking into account that biodiversity is a fundamental requirement to improve the quality of fruits of this important crop, Andean landraces can be an interesting source of genetic variability. ${ }^{26}$ The results revealed a promising breeding perspective, since the incorporation of Andean accessions could reinforce genetic variability and the incorporation of valuable new compounds that could contribute to improve quality of cultivated tomatoes. Finally, to our knowledge this is the first time that Argentinean tomato landraces are studied by their volatile metabolites content and compared with a commercial variety and a wild tomato species.

\section{Supplementary Information}

Supplementary data (Tables of optimization of HSSPME-GC-MS, more details about VOCs quantities in tomato samples) are available free of charge at http://jbcs.sbq.org.br as PDF file.

\section{Acknowledgments}

This work was supported in part by CONICET, SECYT and ANPCyT. P. R. C. gratefully acknowledges receipt of a fellowship from CONICET.

\section{References}

1. Fukusaki, E.; Kobayashi, A.; J. Biosci. Bioeng. 2005, 100, 347.

2. Yang, C.; Wang, J.; Li, D.; Anal. Chim. Acta 2013, 799, 8.

3. Zhang, Z.; Pawliszyn, J.; Anal. Chem. 1993, 65, 1843.

4. Iijima, Y.; Metabolites 2014, 4, 699.

5. Tikunov, Y.; Lommen, A.; de Vos, C. H. R.; Verhoeven, H. A.; Bino, R. J.; Hall, R. D.; Bovy, A. G.; Plant Physiol. 2005, 139, 1125.

6. Figueira, J.; Câmara, H.; Pereira, J.; Câmara, J. S.; Food Chem. 2014, 145, 653.

7. Petro-Turza, M.; Food Rev. Int. 1986, 2, 309.

8. Baldwin, E. A.; Scott, J. W.; Shewmaker, C. K.; Schuch, W.; HortScience 2000, 35, 1013.

9. Goff, S. A.; Klee, H. J.; Science 2006, 311, 815.

10. El Hadi, M.; Zhang, F.-J.; Wu, F.-F.; Zhou, C.-H.; Tao, J.; Molecules 2013, 18, 8200.

11. Asprelli, P. D.; Occhiuto, P. N.; Makuch, M. A.; Lorello, I. M.; Tongo, L. S.; Lampasona, S. C. G.; Peralta, I. E.; Horticultura Argentina 2011, 30, 30.

12. Jordan, J.; Sociol. Ruralis 2007, 47, 20.

13. Watson, B.; Taylor's Guide to Heirloom Vegetables: A Complete Guide to the Best Historic and Ethnic Varieties, $1^{\text {st }}$ ed.; Houghton Mifflin: New York, USA, 1996.

14. Klee, H. J.; Tieman, D. M.; Trends Genet. 2013, 29, 257.

15. Di Rienzo, J. A.; Guzmán, A. W.; Casanoves, F. A.; J. Agric. Biol. Environ. Stat. 2002, 7, 1.

16. Di Rienzo, J. A.; Casanoves, F.; Balzarini, M. G.; Gonzalez, L.; Tablada, M.; Robledo, C. W.; InfoStat versión 2014, Grupo InfoStat, FCA, Universidad Nacional de Córdoba, Argentina, 2014. Available at http://www.infostat.com.ar, accessed in April 2016.

17. Bezman, Y.; Mayer, F.; Takeoka, G. R.; Buttery, R. G.; BenOliel, G.; Rabinowitch, H. D.; Naim, M.; J. Agric. Food Chem. 2003, 51, 722 . 
18. Steffen, A.; Pawliszyn, J.; J. Agric. Food Chem. 1996, 44, 2187.

19. Guinard, J. X.; Marty, C.; J. Food Sci. 1995, 60, 727; Siefarth, C.; Tyapkova, O.; Beauchamp, J.; Schweiggert, U.; Buettner, A.; Bader, S.; Food Res. Int. 2011, 44, 3202.

20. Cheong, K. W.; Tan, C. P.; Mirhosseini, H.; Chin, S. T.; Che Man, Y. B.; Hamid, N. S. A.; Osman, A.; Basri, M.; Food Chem. 2011, 125, 1481.

21. Hübschmann, H. J.; Handbook of GC/MS: Fundamentals and Applications, $2^{\text {nd }}$ ed.; Wiley-VCH Verlag GmbH \& Co. KGaA: Weinheim, Germany, 2008.

22. Silva, B. J.; Tranchida, P. Q.; Purcaro, G.; Queiroz, M. E.; Mondello, L.; Lancas, F. M.; J. Chromatogr. A 2012, 1255, 177.

23. Zanor, M. I.; Rambla, J. L.; Chaïb, J.; Steppa, A.; Medina, A.; Granell, A.; Fernie, A. R.; Causse M.; J. Exp. Bot. 2009, 60, 2139.
24. Tieman, D. M.; Bliss, P.; McIntyre, L. M.; Blandon-Ubeda, A.; Bies, D.; Odabasi, A. Z.; Rodriguez, G. R.; van der Knaap, E.; Taylor, M. G.; Goulet, C.; Mageroy, M. H.; Snyder, D. J.; Colquhoun, T.; Moskowitz, H.; Clark, D. G.; Sims, C.; Bartoshuk, L.; Klee, H. J.; Curr. Biol. 2012, 22, 1035.

25. Socaci, S. A.; Socaciu, C.; Mureşan, C.; Fărcaş, A.; Tofană, M.; Vicaş, S.; Pintea, A.; Phytochem. Anal. 2014, 25, 161.

26. Corrado, G.; Caramante, M.; Piffanelli, P.; Rao, R.; Sci. Hort. 2014, 168, 138.

Submitted: February 2, 2016

Published online: May 6, 2016 